\title{
Angleterre. Un mythe professionnel en souffrance
}

Études de cas

Régis Malet

\section{CpenEdition}

Journals

Édition électronique

URL : https://journals.openedition.org/ries/1309

DOI : 10.4000/ries.1309

ISSN : 2261-4265

Éditeur

France Education international

Édition imprimée

Date de publication : 1 décembre 2005

Pagination : 97-99

ISSN : 1254-4590

Référence électronique

Régis Malet, "Angleterre. Un mythe professionnel en souffrance », Revue internationale d'éducation de Sèvres [En ligne], 40 | décembre 2005, mis en ligne le 17 novembre 2011, consulté le 06 juillet 2021. URL : http://journals.openedition.org/ries/1309 ; DOI : https://doi.org/10.4000/ries.1309

Ce document a été généré automatiquement le 6 juillet 2021

(c) Tous droits réservés 


\section{Angleterre. Un mythe professionnel en souffrance}

Études de cas

Régis Malet

1 Les enseignants anglais, en référence à des professions établies, affirment traditionnellement leur professionnalisme par leur influence en matière de choix des contenus d'enseignement et par l'affichage d'une éthique et d'une responsabilité professionnelle élargie, garantes d'une position sociale reconnue et d'une autonomie d'exercice.

\section{La crise de confiance}

2 Ce professionnalisme sur lequel le corps enseignant britannique a construit son identité et sa légitimité n'a de validité que si le politique, et la société elle-même, lui accordent crédit et confiance. Or ce contrat moral entre la nation et les enseignants semble aujourd'hui défaillant. Depuis les années 1980, les gouvernants britanniques, de la Nouvelle Droite (New Right), puis de la Nouvelle Gauche (New Labour), ont repris le pouvoir sur l'école et un corps enseignant qui, du fait de son histoire et de ses formes de légitimation, est moins protégé que ne l'est le monde enseignant français par un lien organique entre l'École, les maîtres et l'État.

3 La "désuniversitarisation" de la formation, la standardisation des compétences professionnelles, l'élargissement et la technicisation des tâches, l'imputabilité des enseignants (accountabiliy), sont autant d'indicateurs de la mise en faillite du mythe professionnel et de l'idéal d'autonomie dont il était porteur. Cette crise de confiance et ses conséquences en termes de procéduralisation du travail, auxquels se conjuguent les difficultés, communes avec la France, liées à la diversification des publics scolaires dans un enseignement de masse, engendrent chez les enseignants britanniques des doutes identitaires et des incertitudes sur leur capacité à assumer les missions qu'on leur assigne ${ }^{1}$. 


\section{Des évolutions contradictoires}

4 Sur un plan politique, les indices de ces évolutions se déclinent selon un double mouvement, de globalisation et de fragmentation des politiques scolaires: renforcement de l'autonomie (maîtrisée) des établissements, contractualisation des objectifs éducatifs et développement du management participatif, déconcentration du pouvoir hiérarchique, individualisation des carrières des personnels enseignants, accroissement du pouvoir parental (Gewirtz, Ball \& Bagley, 1995), passage d'une logique administrative de gestion des personnels, à une logique managériale de gestion des ressources humaines (Laderrière, 2004), développement d'outils d'évaluation des élèves, des enseignants et des établissements (Broadfoot, 1996; Lessard \& Meirieu, 2005). Ces diverses évolutions, observables dans la plupart des pays européens selon une intensité variable, sont largement réalisées en Angleterre.

5 Singulièrement, dans un pays de tradition communautariste dans lequel la culture organisationnelle a pénétré l'univers scolaire bien longtemps avant la France, on voit se développer des formes de régulation du travail scolaire hybrides, marquées à la fois par un modèle libéral conférant aux établissements une marge d'autonomie importante dans le recrutement et les carrières de leurs personnels et dans leurs liens avec l'environnement social et économique, et par un modèle bureaucratique plus récent, l'État s'accordant un rôle de contrôle renforcé des établissements et des personnels qui y exercent. Responsables jusqu'alors auprès de leur employeur, l'établissement et les autorités éducatives locales, les écoles et les enseignants le sont dorénavant auprès de l'État (Malet \& Brisard, 2005). Ces évolutions voient émerger des formes d'administration scolaire promouvant des notions managériales, singulièrement marquées par des préoccupations éthiques - school improvement, school effectiveness, educational and management - en conformité avec les principes qui animent le New Labour (associant réalisme économique, souci d'efficacité et justice sociale).

6 Au-delà de ce diagnostic global et programmatique, l'objectif est aussi d'examiner comment les évolutions récentes des conditions d'exercice et les «injonctions au changement » des pratiques transforment le métier d'enseignant, compte tenu de cultures professionnelles, organisationnelle et de formes d'accompagnement spécifiques. L'un des enjeux est également d'examiner les formes de leadership observables, dans les établissements scolaires britanniques, par des administrateurs qui sont les interfaces décisives entre les incitations institutionnelles et les enseignants. Il est enfin de mettre en perspective les formes d'accompagnement, de responsabilisation et de reconnaissance auxquelles donnent lieu ces velléités d'élargissement des missions et du travail des enseignants.

7 En Angleterre comme dans d'autres pays européens, les transformations des formes d'administration de l'école et des enseignants attestent d'une ambition claire : il s'agit d'assurer une autorité effective de l'autorité macro-politique avec un État fort, tout en accordant une autonomie de gestion au niveau micro-politique des établissements : au prix d'un affaiblissement du potentiel des autorités éducatives locales, devenu embarrassant, et de la promotion d'un modèle de conformation professionnel promoteur, pour ce qui est du travail des enseignants, de ce que j'appellerais un "différentiel normé ». Il semble que le politique œuvre à combiner une norme professionnelle locale plus ou moins sédimentée, avec la tendance internationale au 
développement de formes de pilotage scolaire fondées sur la rationalisation et la responsabilisation individuelle et collective.

Il convient probablement d'interroger, en le plaçant sur un plan international, ce double processus de rationalisation/responsabilisation du travail des enseignants, dont l'aboutissement visé est le développement d'une culture du collectif, d'un professionnalisme collectif. Il vise à permettre, à terme, la mutualisation et l'harmonisation des ressources et des pratiques propres à une communauté éducative, dans une perspective de rationalisation collective de l'offre de formation. De ce point de vue, la promotion de l'organisation scolaire apprenante à l'œuvre depuis la dernière décennie trouve matière ici et là, avec l'introduction de nouvelles formes de management social des établissements, et en particulier dans le contexte anglais, à armer les réformes éducatives en cours d'un arsenal de «technologies de gouvernance » (Ball, 2003) qui en assurent la mise en œuvre locale.

\section{BIBLIOGRAPHIE}

BROADFOOT P. (1996): Education, Assessment and Society, Buckingham: Open University Press.

GEWIRTZ S., BALL S. \& BOWE R. (1995): Markets, Choice and Equity in Education, Buckingham: Open University Press.

LADERRIÈRE P. (2004) : La Gestion des ressources humaines dans l'enseignement : où en est l'Europe ?, Paris : L'Harmattan.

LESSARD C. \& MEIRIEU P. (Dir.) (2005) : L'obligation de résultats en éducation. Évolutions, perspectives et enjeux internationaux, Bruxelles : De Boeck.

MALET R. \& BRISARD E. (Dir.) (2005) : Modernisation de l'école et contextes culturels. Des politiques aux pratiques en France et en Grande-Bretagne, préface d'Agnès van Zanten, Paris : L'Harmattan.

\section{NOTES}

1. Si la plupart des nations européennes sont exposées à des risques de pénurie d'enseignants, la Grande-Bretagne (à l'exception notable de l'Écosse), est parmi les pays les plus touchés par cette désaffection pour la profession et par les décisions d'abandon au cours des premières années dans le métier (Commission Européenne, 2004 ; Leclecq, 2003). Les mesures d'incitation par des primes d'accueil offertes aux néo-enseignants (le Golden Hello), ne suffisent pas à combler cette pénurie, à tel point que des formations alternatives ont été introduites. Le Graduate and Registered Teacher Programmes (GRTP) en Angleterre et au Pays de Galles est une nouvelle voie de formation en emploi qui permet aux établissements de recruter des personnes non qualifiées pour l'enseignement et de les former dans un programme de formation individuel qui mène au Qualified Teacher Status (statut d'enseignant qualifié). 
INDEX

Index géographique : Angleterre, Royaume-Uni

\section{AUTEUR}

RÉGIS MALET

Maître de conférences, Université Charles de Gaulle - Lille 3. 